\title{
Pitfalls and premature failure of the Freedom SOLO stentless valve
}

\author{
Olaf Stanger ${ }^{a, *}$, Irina Bleuel ${ }^{a}$, Sylvia Reineke ${ }^{a}$, Yara Banz ${ }^{b}$, Gabor Erdoesc, Hendrik Tevaearai ${ }^{a}$, Volkhard Göbera, \\ Thierry Carrel $^{\mathrm{a}}$ and Lars Englberger ${ }^{\mathrm{a}}$
}

a Clinic for Cardiovascular Surgery, Inselspital, Bern University Hospital and University of Bern, Bern, Switzerland

b Institute of Pathology, University of Bern, Bern, Switzerland

c Department of Anesthesiology and Pain Therapy, Inselspital, Bern University Hospital, Bern, Switzerland

* Corresponding author. Clinic for Cardiovascular Surgery, Inselspital, University Hospital, Freiburgstrasse 18, CH-3010 Bern, Switzerland. Tel: +41-791-932951; fax: +41-316-329766; e-mail: olaf.stanger@insel.ch (O. Stanger).

Received 1 September 2014; received in revised form 7 November 2014; accepted 11 November 2014

\begin{abstract}
OBJECTIVES: This study reports a series of pitfalls, premature failures and explantations of the third-generation Freedom SOLO (FS) bovine pericardial stentless valve.

METHODS: A total of 149 patients underwent aortic valve replacement using the FS. Follow-up was $100 \%$ complete with an average observation time of $5.5 \pm 2.3$ years (maximum 8.7 years) and a total of 825 patient-years. Following intraoperative documentation, all explanted valve prostheses underwent histological examination.

RESULTS: Freedom from structural valve deterioration (SVD) at 5, 6, 7, 8 and 9 years was $92,88,80,70$ and $62 \%$, respectively. Fourteen prostheses required explantation due to valve-independent dysfunction $(n=5$; i.e. thrombus formation, oversizing, aortic dilatation, endocarditis and suture dehiscence) or valve-dependent failure (acute leaflet tears, $n=4$ and severe stenosis, $n=5$ ). Thus, freedom from explantation at 5, 6, 7, 8 and 9 years was 95, 94, 91, 81 and 72\%, respectively. An acute vertical tear along the non-coronary/right coronary commissure to the base occurred at a mean of 6.0 years (range 4.3-7.3 years) and affected size 25 and 27 prostheses exclusively. Four FS required explantation after a mean of 7.5 years (range $7.0-8.3$ years) due to severe functional stenosis and gross calcification that included the entire aortic root.
\end{abstract}

CONCLUSIONS: The FS stentless valve is safe to implant and shows satisfying mid-term results in our single institution experience. Freedom from SVD and explantation decreased markedly after only 6-7 years, so that patients with FS require close observation and follow-up. Exact sizing, symmetric positioning and observing patient limitations are crucial for optimal outcome.

Keywords: Aortic valve $\cdot$ Stentless $•$ Bioprosthesis $•$ Cardiac surgery

\section{INTRODUCTION}

Aortic valve replacement (AVR), usually with a biological prosthesis, is the treatment of choice for severe and symptomatic aortic valve disease [1]. Stentless bioprostheses were introduced to clinical practice as an attractive alternative to stented valves, with excellent early clinical and haemodynamic results [2]. Freedom from structural valve deterioration (SVD) and reoperation can be influenced by the tissue structure (e.g. bovine versus porcine), the design of the valve, its mechanical wear and stress absorption properties; notably, chemical fixation and the anticalcification treatment are considered as key elements in valve manufacturing aimed at enhancing valve durability [3].

The third-generation Freedom SOLO (FS) aortic valve bioprosthesis (Sorin Group, Saluggia, Italy), introduced in June 2004, is made of two bovine pericardial sheets for supra-annular subcoronary implantation. The design is intended to preserve left ventricular-aortic root coupling, which is thought to be essential to protect aortic valve function by decreasing mechanical stress on the leaflets and particularly the commissures, where structural failure and calcification typically originate [4]. In addition, the FS employs a unique manufacturing process to include homocysteic acid (HCA) as an anticalcification treatment to bind and neutralize free glutaraldehyde (GA) residues.

Our institution introduced the FS very early on. We [5] and others [6] had reported a favourable early outcome with excellent haemodynamic results for the FS. We now present, however, our experience with valve-related and -non-related failures and reoperations involving the FS after up to 8.7 years of observation. 


\section{METHODS}

\section{Patient population}

Between January 2005 and November 2009, 149 patients (mean age $73.6 \pm 8.7$ years, 68 [45.6\%] female) in our department underwent isolated $(n=75)$ or combined $(n=74)$ AVR with the FS valve. The decision to use the FS stentless valve or an alternative conventional stented prosthesis was at the surgeon's discretion in accordance with the patient's wishes. The FS stentless valve was not considered suitable in cases with severe calcification of the supra-annular sinus. The local ethics committee approved review of the data and patient consent was waived for the retrospective analysis. The patients' characteristics are given in Table 1. One patient was operated on with acute bacterial endocarditis, and 4 cases were redo procedures. Twenty patients $(13.4 \%)$ had a left ventricular ejection fraction of $\leq 40 \%$ at the time of surgery.

\section{Surgical and postoperative management}

AVR procedures were all performed under routine general anaesthesia and with median sternotomy, using standard cardiopulmonary bypass and mild hypothermia $\left(34^{\circ} \mathrm{C}\right)$. Cold blood cardioplegia was routinely used for myocardial protection. Aortotomy was

Table 1: Patient characteristics

$\begin{array}{ll}\text { Number of patients } & 149 \\ \text { Age (years), mean } \pm \text { SD } & 73.6 \pm 8.7(47.2-87.4) \\ \text { Gender } & \\ \text { Male }(n, \%) & 81(54.4) \\ \text { Female }(n, \%) & 68(45.6) \\ \text { BMI }\left(\mathrm{kg} / \mathrm{m}^{2}\right), \text { mean } \pm \text { SD } & 27.0 \pm 6.5(18.3-46.3) \\ \left.\text { BSA (Dubois, m }{ }^{2}\right), \text { mean } \pm \text { SD } & 1.81 \pm 0.29(1.38-2.30) \\ \text { Diabetes mellitus }(n, \%) & 34(22.8) \\ \text { Arterial hypertension }(n, \%) & 130(87.2) \\ \text { Renal impairment }(n, \%) & 24(16.1) \\ \text { LVEF }(\%) & 53.7 \pm 12.3 \\ \text { NYHA class } & \\ \text { I } & 14(9.4) \\ \text { II } & 62(41.6) \\ \text { III } & 54(36.2) \\ \text { IV } & 19(12.8) \\ \text { Aortic valve pathology } & \\ \text { Stenosis } & 126(84.6) \\ \text { Regurgitation } & 10(6.7) \\ \text { Combined } & 13(8.7) \\ \text { Labelled valve size } & \\ \# 19 & 3(2.0) \\ \text { \#21 } & 28(18.8) \\ \text { \#23 } & 44(29.5) \\ \# 25 & 39(26.2) \\ \text { \#27 } & 35(23.5) \\ \text { Combined procedures } & \\ \text { CABG } & 79(53.0) \\ \text { MVR (DVR) } & 7(4.7) \\ \text { Other }{ }^{2} & 17(11.4) \\ & \end{array}$

Values are $n(\%)$ or mean $\pm S D$ (range).

LVEF: left ventricular ejection fraction; MVR: mitral valve repair/ replacement; CABG: coronary artery bypass grafting; DVR: double valve replacement.

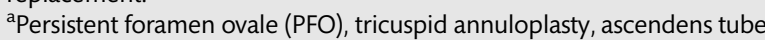
graft, ablation performed $\sim 1 \mathrm{~cm}$ above the sinotubular junction (STJ). The diseased valve was then excised and the annulus carefully decalcified. The FS valve was implanted without rinsing in the supra-annular subcoronary position, with continuous suture lines using 4/0 prolene monofilament in the sinuses of Valsalva. In brief, the sutures started at the base of each sinus and followed to the top of the commissures ending in extra-aortic fixation. Transoesophageal echocardiography (TOE) was routinely performed intraoperatively before and after AVR to assess and document prosthesis function. Patients with the FS valve require no regular anticoagulation after hospital discharge.

\section{Data collection and follow-up}

Perioperative data were retrieved from our prospectively managed institutional database (Dendrite Clinical Systems Ltd, Henleyon-Thames, UK). All patients were routinely examined with transthoracic echocardiography before hospital discharge, at 6 months and yearly thereafter. Transvalvular pressure gradients and the effective orifice area (EOA) were calculated using the modified Bernoulli equation and the continuity equation, respectively. Mortality and morbidity (rate of adverse events) were reported according to the established guidelines [7]. These guidelines define structural valve deterioration (SVD) as change in function or deterioration of an operated valve resulting from an intrinsic abnormality of the valve that causes stenosis or regurgitation, exclusive of infection or thrombosis. SVD includes wear, fracture, poppet escape, calcification, leaflet tear, stent creep and suture line disruption of an operated valve [7]. Clinical status and adverse events were carefully assessed at each visit or by consultation with the referring physician. The follow-up was $100 \%$ complete with a cumulative total observation of 825 patient-years (mean $5.5 \pm 2.3$ years [maximum 8.7 years]).

\section{Histology}

Following intraoperative photodocumentation, all explanted valve prostheses were immediately fixed in $10 \%$ neutral-buffered formalin solution for at least $24 \mathrm{~h}$. The valves were then processed in their entirety by standard procedures, embedded in paraffin, decalcified as needed, cut into $3 \mu \mathrm{m}$ sections and stained with haematoxylin and eosin as well as Elastica van Gieson for histological examination.

\section{Statistical analysis}

Probabilities of freedom from death and freedom from explantation for SVD were estimated by Kaplan-Meier actuarial analysis. Demographic data are summarized by mean and shown with standard deviation for continuous variables and by percentages for categorical variables. All statistical analyses were performed using the Stata statistical software package 12.0 (SPSS, Inc., Chicago, IL, USA). Outcome data are presented as operative mortality, defined as death from any cause during or after surgery within 30 days if the patient was discharged, or within any interval if the patient was not discharged [7].

\section{RESULTS}

Operative mortality was $2.7 \%$ ( $n=4$, all combined procedures) and 46 additional patients died during the observation period (44 of 
them without reoperation, Fig. 1). Freedom from SVD at 5, 6, 7, 8 and 9 years was $92,88,80,70$ and $62 \%$, respectively. Initial AVR procedures were uneventful in 14 patients who later required explantation of their FS prostheses for structural $(n=9)$ and nonstructural $(n=5)$ causes that are reported in more detail in Table 2. Thus, freedom from explantation at 5, 6, 7, 8 and 9 years was 95, $94,91,81$ and $72 \%$, respectively.

\section{Prosthesis replacement due to non-structural dysfunction}

Case 1. The patient was re-admitted with acute dyspnoea and pulmonary oedema 5 months after combined CABG and AVR. Coronary angiography showed patent bypass grafts, and TOE showed normal morphology and function of the right (RCC) and left coronary cusps (LCC). The non-coronary cusp (NCC), however, was found immobile and adherent to the aortic wall resulting in severe regurgitation with haemodynamic instability necessitating reoperation. A large thrombotic adhesion on the NCC found intraoperatively was shown by histology to cause the attachment (Fig. 2), but there was no other structural damage. Despite an uncomplicated replacement with a stented prosthesis and early recovery, the patient suddenly fell into cardiac arrest on the eighth postoperative day and died. Post hoc analysis of the TOE records showed intercommissural distances of $24.8 \mathrm{~mm}$ (NCC), $27.3 \mathrm{~mm}$ (LCC) and $27.4 \mathrm{~mm}$ (RCC), respectively.

Case 2. Postoperative FS function was satisfactory in this patient with an indexed EOA (iEOA) of 1.01 and a mean gradient of $11.5 \mathrm{mmHg}$. The aortic dimensions for the annulus, aortic sinus, STJ and ascending aorta were 19, 22.5, 20 and $28 \mathrm{~mm}$, respectively. After 1 month, the transvalvular gradients had slightly increased to $31 / 16 \mathrm{mmHg}$, and the iEOA had decreased to 0.89 . One year later, all cusps showed evidence of degeneration with a transvalvular leak between the RCC/NCC and eccentric jets (mild-to-moderate regurgitation). Another 6 months later, all three leaflets degenerated severely and showed limited or absent (RCC) movements with gradients of $98 / 66 \mathrm{mmHg}$ and an iEOA of 0.32 , graded as severe stenosis (and moderate-to-severe regurgitation; Fig. 3). The cause was judged intraoperatively to be folding of the RCC and NCCs due to oversizing, with signs of diffuse degeneration. Post hoc, the cusp areas for NCC, LCC and

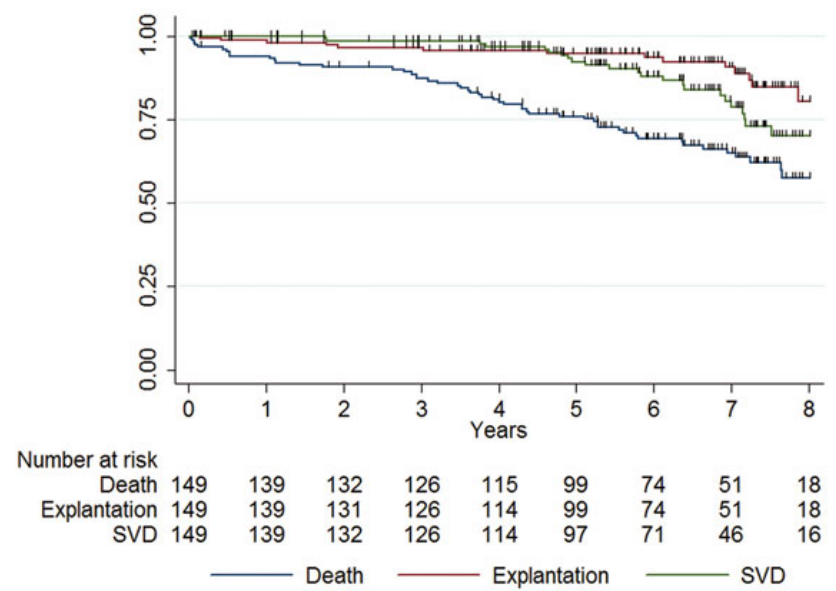

Figure 1: Kaplan-Meier estimates for death, explantation and structural valve degeneration.
RCC after 12 and 20 months were found to be $1.01(1.07) \mathrm{cm}^{2}$, $1.09(1.08) \mathrm{cm}^{2}$ and $1.34(1.26) \mathrm{cm}^{2}$, respectively.

Case 3. The patient underwent AVR because of severe aortic regurgitation, with a dilated and hypertrophic left ventricle [left ventricular enddiastolic diameter (LVEDD) $64 \mathrm{~mm}$ ] and cardiomyopathy (EF 15\%). The diameters for the annulus, aortic sinus, STJ and ascending aorta were 33, 43, 38 and $40 \mathrm{~mm}$, respectively. The patient was discharged 7 days after AVR with improved EF (25\%), in sinus rhythm, with competent valve function with a mean gradient of $14 \mathrm{mmHg}$. Aortic regurgitation was first noted 2 months later, and was further classified as moderate and then severe after 5 and 8 months, respectively. The regurgitation fraction increased from 36 to 53 and 70\%, and the corresponding LVEDD increased to 68 and $76 \mathrm{~mm}$, respectively. At reoperation, the valve was found to be normal and the aortic STJ further dilated (44 mm).

Case 4. After combined $C A B G$ and $A V R$, close observation was advised as there was some evidence of mild-to-moderate regurgitation and gradients of $43 / 25 \mathrm{mmHg}$ at discharge. Nonetheless, the follow-up investigation 2 years later showed severe regurgitation combined with functional stenosis (gradients $88 / 44 \mathrm{mmHg}, V_{\max } 4.7 \mathrm{~m} / \mathrm{s}$, pressure half time (PHT) $214 \mathrm{~ms}$ and EOA $2.2 \mathrm{~cm}^{2}$ ). At reoperation, the NCC was found completely dehiscent from the annulus with paravalvular leakage. There were no histological signs of degenerative valve changes.

Case 5. The patient caught a cold some weeks after uncomplicated AVR and declined physically after unsuccessful treatment with antibiotics. Coagulase-negative staphylococci were detected in 4/4 blood cultures. When infective endocarditis with vegetation was confirmed intraoperatively, the valve replaced uneventfully.

\section{Prosthesis replacement due to structural valve deterioration}

Leaflet tears. Four male patients with initially uneventful AVR (FS sizes $27[n=3]$ and $25[n=1])$ all presented with acute dyspnoea, cardiac failure and severe aortic regurgitation after a mean of 6.2 years (4.6-7.3 years). Importantly, each case featured a sharp vertical tear along the NCC/RCC commissure to the base (Fig. 4). No valve showed any evidence of endocarditis, and aortic dimensions were normal at all times.

Case 6. Gradients after AVR were $11.7 / 6.6 \mathrm{mmHg}$ with an EOA of $2.54 \mathrm{~cm}^{2}$. Intercommissural distances were $27.2 \mathrm{~mm}$ (NCC), $26.2 \mathrm{~mm}$ (LCC) and $27.4 \mathrm{~mm}$ (RCC) in the post hoc analysis. The patient was re-admitted after 4.6 years with acute cardiac failure and underwent urgent reoperation. A sharp and vertical tear in the RCC was found just next to the NCC/RCC commissure.

Case 7. The patient was re-admitted with acute aortic regurgitation. A sharp tear of the NCC next to the NCC/RCC commissure was found intraoperatively (Fig. 4A).

Case 8. The patient was re-admitted with acute severe aortic regurgitation (PHT: $110 \mathrm{~ms}$ ) and moderate mitral regurgitation. Again, a sharp tear of the NCC next to the NCC/RCC commissure was found intraoperatively (Fig. 4B). The prosthesis was replaced in the course with mitral valve repair/replacement and CABG. Redundant intramural haematoma necessitated concomitant tube replacement of the ascending aorta. Despite the extensive procedure, the patient recovered well and was discharged on the 10th postoperative day. 
Table 2: Case series

\begin{tabular}{|c|c|c|c|c|c|c|c|c|c|}
\hline Case & $\begin{array}{l}\text { Sex, age (years) } \\
\text { at AVR }\end{array}$ & Indication & FS & $\begin{array}{l}\text { Explant after } \\
\text { (years) }\end{array}$ & Symptoms & $\begin{array}{l}\text { New } \\
\text { prosthesis }\end{array}$ & $\begin{array}{l}\text { Concomitant } \\
\text { procedure }\end{array}$ & Cause & Discharge \\
\hline 1 & $\sigma^{7}, 76$ & AS & $\# 27$ & 0.4 & $\begin{array}{l}\text { Moderate } \\
\text { AR }\end{array}$ & \#23 PM & & Thrombus (NCC) & Dead \\
\hline 2 & $\sigma^{2}, 62$ & AS & \#23 & 1.8 & $\begin{array}{l}\text { Severe } \\
\quad A R+A S\end{array}$ & \#21 PM & Root enlargement & Oversizing, degeneration & Alive \\
\hline 3 & $0^{\prime}, 65$ & AR & \#27 & 1.0 & Severe AR & \#25 PM & & Dilated STJ & Alive \\
\hline 4 & $\sigma^{\prime \prime}, 70$ & AR & \#23 & 1.9 & $\begin{array}{l}\text { Severe } \\
\quad \text { AR + AS }\end{array}$ & \#23 PM & & NCC dehiscence & Alive \\
\hline 5 & Q, 75 & AS & $\# 27$ & 0.2 & $\begin{array}{l}\text { Moderate } \\
\text { AR }\end{array}$ & \#25 PM & Abscess patch & Endocarditis & Alive \\
\hline 6 & $0^{2}, 69$ & AS & \#27 & 4.3 & Severe AR & \#25 PM & & $\begin{array}{l}\text { Vertical tear (RCC) near } \\
\text { commissure }\end{array}$ & Alive \\
\hline 7 & $0^{2}, 64$ & AS & $\# 27$ & 6.4 & Severe AR & \#25 PM & & $\begin{array}{l}\text { Vertical tear (NCC) near } \\
\text { commissure }\end{array}$ & Alive \\
\hline 8 & $\sigma^{2}, 54$ & $\mathrm{BAV}, \mathrm{AR}$ & $\# 27$ & 6.2 & Severe AR & \#23 PM & MVR, CABG, TVR & $\begin{array}{l}\text { Vertical tear (NCC) near } \\
\text { commissure }\end{array}$ & Alive \\
\hline 9 & $0^{\prime \prime}, 76$ & AS & $\# 25$ & 7.3 & Severe AR & \#21 PM & & $\begin{array}{l}\text { Vertical tear (NCC) near } \\
\text { commissure }\end{array}$ & Alive \\
\hline 10 & $\circ, 63$ & AS & \#19 & 7.2 & Severe AS & \#19 PM & Root enlargement & Calcification & Alive \\
\hline 11 & $q, 60$ & AR/AS & \#23 & 7.9 & Severe AS & \#20 ATS & & Calcification & Alive \\
\hline 12 & 0,66 & AS & \#23 & 8.3 & Severe AS & \#21 PM & & Calcification & Alive \\
\hline 13 & $q, 56$ & AS & \#21 & 7.0 & Severe AS & \#19 PM & ECMO, TVR & Calcification & Dead \\
\hline 14 & $0^{\prime \prime}, 62$ & AR/AS & \#23 & 7.0 & Severe AS & \#21 PM & CABG & Calcification & Alive \\
\hline
\end{tabular}

AR: aortic regurgitation; AS: aortic stenosis; BAV: bicuspid aortic valve; RCC: right coronary cusp; CABG: coronary arterial bypass grafting; NCC: non-coronary Cusp; TVR: tricuspid valve repair (replacement); MVR: mitral valve repair (replacement); STJ: sinotubular junction; ECMO: extracorporeal membrane oxygenation; PM: Perimount; FS: freedom SOLO.


Figure 2: Immobile non-coronary cusp due to thrombus formation on the leaflet (Case 1).

Case 9. Light-to-moderate sclerosis was first recorded 3 years after AVR in a fully competent valve. There was no increase of gradients in subsequent controls, and the patient was well and active until he felt a sudden decrease in physical capacity. A vertical tear in the NCC was found just next to the NCC/LCC commissure, together with a severely restricted RCC movement.

Degeneration and severe calcification. Four female patients required explantation of the FS after a mean of 7.6 years (7.0-8.3 years) due to severe calcification and functional stenosis (Fig. 5). All FS valves were very difficult to replace and in each case a stented valve at least one size smaller was used. It is important to note that annulus shrinkage and gross calcification always included the aortic root. Cusps consistently showed a dull matt and rough ventricular surface and a glossy smooth sclerotic aortic surface (Fig. 5E).

Case 10. The patient had previously received a CABG and underwent uneventful AVR as a redo procedure. The valve prosthesis developed severe stenosis (EOA $0.3 \mathrm{~cm}^{2}$, Fig. $5 \mathrm{~A}$ ) 7.2 years later and was replaced after extensive decalcification and root enlargement with a stented valve (size 19).

Case 11. Early postoperative gradients following AVR were $18 / 10 \mathrm{mmHg}$. They remained stable until they began to increase 

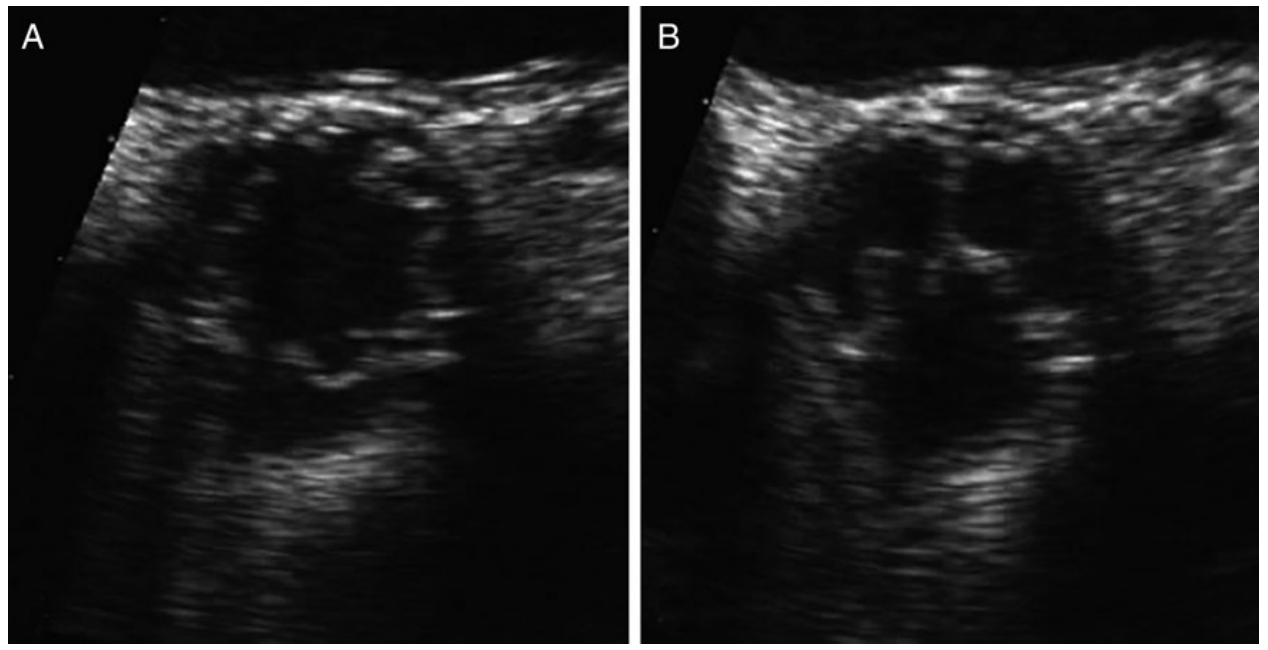

Figure 3: Echocardiography showing a Freedom SOLO valve in systole (A) and diastole (B). Twenty-one months after aortic valve replacement (Case 2).
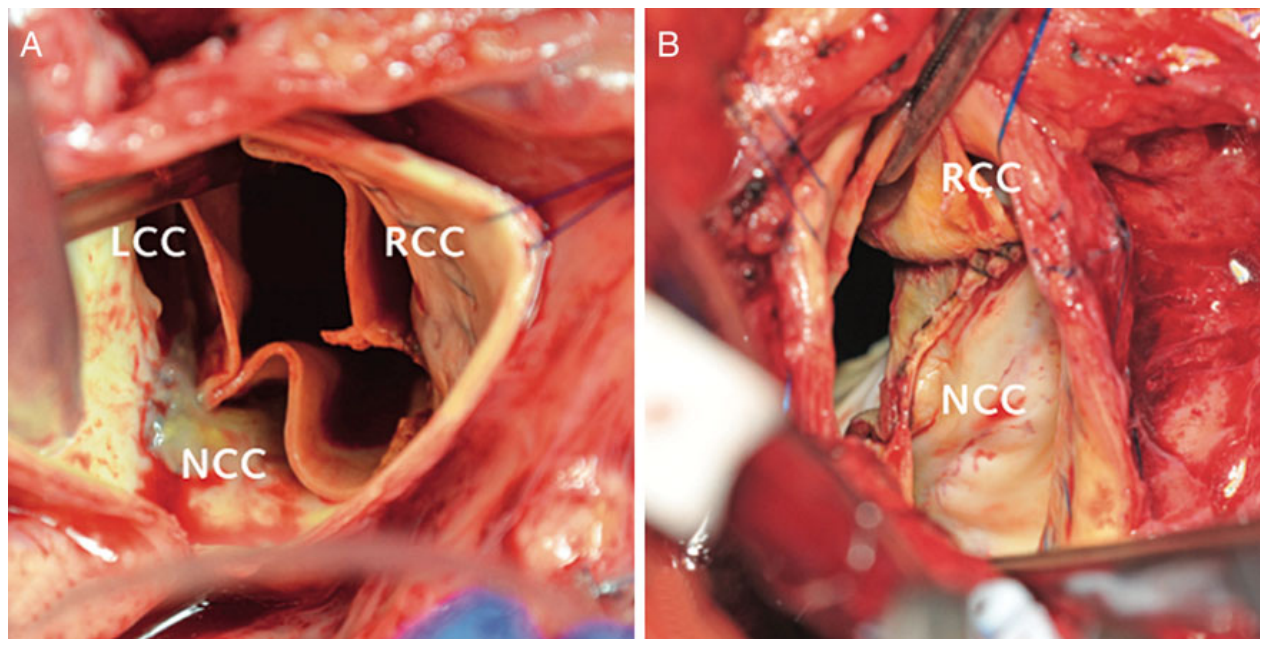

Figure 4: Tear of Freedom SOLO with acute regurgitation at NCC/RCC commissure. Case 7 (A) and Case 8 (B). NCC: non-coronary cusp; RCC: right coronary cusp; LCC: left coronary cusp.

notably in the fifth postoperative year. Despite severe COPD (Gold IV), the patient underwent reoperation because of rapid physical decline, an EOA of $0.45 \mathrm{~cm}^{2}$ and elevated pulmonary pressures. All cusps were found immobile and were severely calcified with a rough ventricular surface and smooth sclerotic aortic surface. The replacement required extensive and aggressive decalcification (Fig. 5B and C).

Case 12. Gradients in this patient were $14 / 8 \mathrm{mmHg}$ after AVR, but began to increase in the second postoperative year. The severely stenotic prosthesis (EOA $0.3 \mathrm{~cm}^{2}$ ) was replaced after extensive decalcification (Fig. 5D) with a stented prosthesis two sizes smaller.

Case 13. The patient underwent AVR with early postoperative gradients of $11 / 5 \mathrm{mmHg}$ that increased continually to $84 / 49 \mathrm{mmHg}$ in the seventh postoperative year with an EOA of $0.3 \mathrm{~cm}^{2}$. All cusps were found to be completely immobile. The prosthesis was replaced with great difficulty due to a shrunken and grossly calcified root. The case was complicated by right ventricular failure, ECMO and tricuspid valve repair, so that the patient eventually failed to survive.

Case 14. The patient noted progressive dyspnoea and decline in physical capacity. TOE showed stiff leaflets and a completely immobile RCC, with a partly fused NCC/LCC commissure $(3.4 \mathrm{~mm}$ length) and a gradient at rest of $57 / 28 \mathrm{mmHg}$. Post hoc analysis of the TOE records showed intercommissural distances before and after commissure fusion of $17.3 \mathrm{~mm}$ (13.9 mm, NCC), $15.4 \mathrm{~mm}$ (13.2 mm, LCC) and $15.2 \mathrm{~mm}$ (15.2 mm, RCC), respectively.

\section{Histology}

On histological examination, the explanted valves with macroscopic sclerosis revealed extensive, band-like calcification within the central part of the prosthesis, accompanied in general by moderate fibrosis on either side (Fig. 6). Foreign body reactions, relevant inflammation, necrosis and bacterial colonization in the setting of infectious endocarditis were not found. Neither relevant mononuclear (macrophages or lymphocytes) nor polymorphonuclear infiltrates were observed in any of the explanted valves. The explanted leaflets commonly showed a rough ventricular surface with microscopic tears in some specimen (Figs 5E and 6). The valves with macroscopically visible tears showed no further pathology, and in particular no prominent inflammatory infiltrate within the area of the tear. Neointima formation, if present, was minimal. 

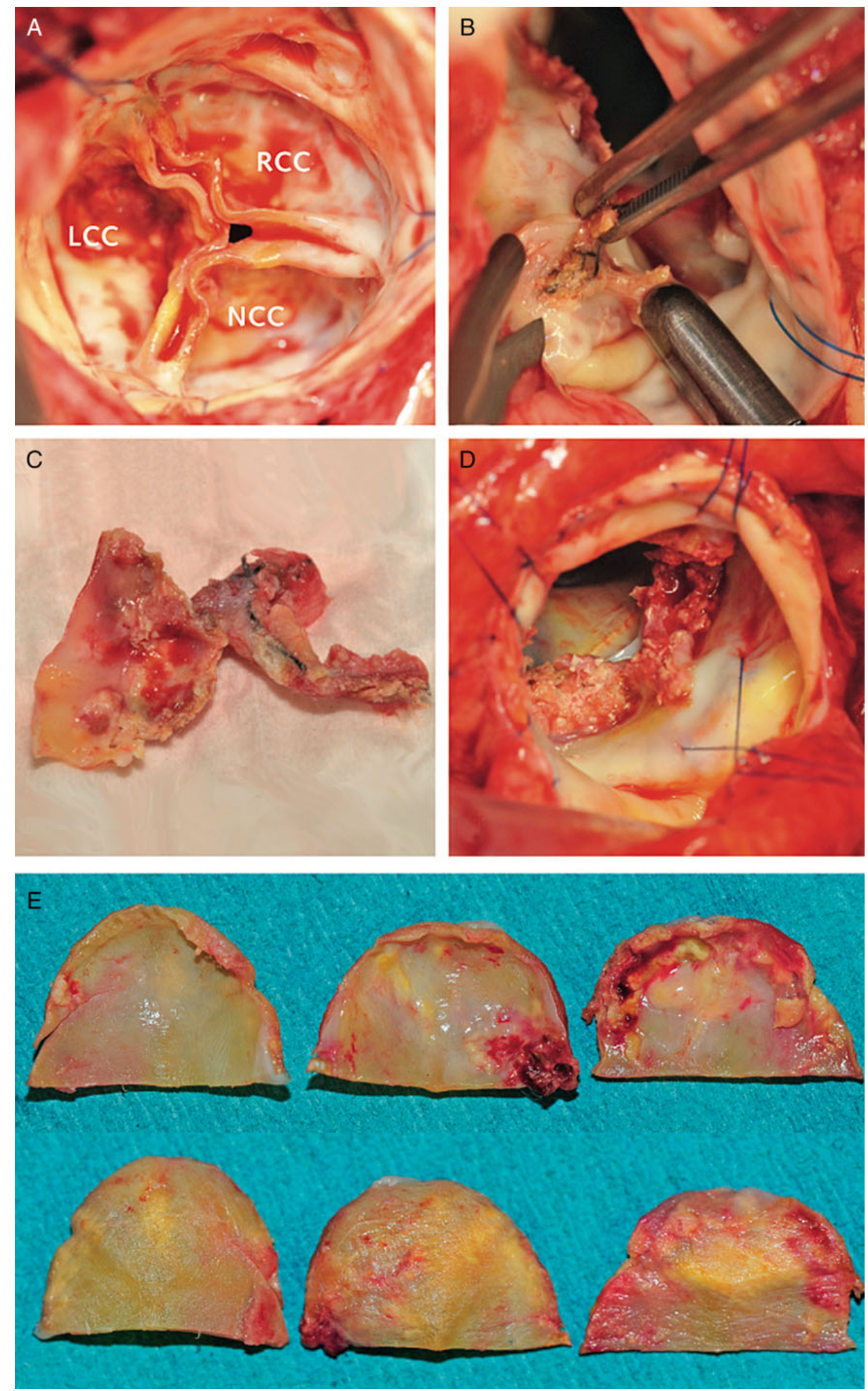

Figure 5: Sclerosis and decalcification. NCC: non-coronary cusp; RCC: right coronary cusp; LCC: left coronary cusp.

\section{DISCUSSION}

We report 14 cases of prosthesis explantation due to structural $(n=9)$ and non-structural $(n=5)$ valve failure among 149 consecutive patients who received an FS stentless valve. In all cases of non-sclerotic SVD, acute vertical tears of the NCC were located in close proximity commissure, and in our series they occurred, on average, 1.5 years (6.0 vs 7.5 years) earlier than explantation for degenerative stenosis. Calcification was always strikingly severe and included the entire aortic root. 



Figure 6: Two examples of degenerated valve prosthesis (haematoxylin and eosin staining). (A) A band-like calcification within the central portion of the valve (white arrows). Minimal fibrin and platelet deposits are noted focally on the surface (black arrow). (B) A similar picture, although less calcification is observed (white arrow) and more dense fibrosis/sclerosis can be noted (black star). Absence of inflammatory infiltrates and neovascularization.

Though it is usually easy to determine the correct valve size, when the manufacturer's recommendations are followed, there can be tough cases. When in doubt, one should consider that oversizing the FS (and other stentless valves) may result in $\mathrm{S}$-shaped leaflet folding with functional stenosis and high gradients [8]. Another source of dysfunction can be the presence or likelihood of future root and/or STJ dilatation with the potential to cause regurgitation [9]. The FS features redundant leaflet tissue for a relatively large coaptation area that compensates for mismatches at the sinotubular ridge during diastole and thus provides greater tolerance to STJ dilatation when compared with other stentless valves [8]. This means that both oversizing and undersizing (particularly in combination with root dilatation) have the potential to cause prosthesis failure. Asymmetric implantation will cause the valve to become distorted with eccentric regurgitation, potentially resulting in increased chronic mechanical stress and premature valve deterioration. Symmetric implantation, however, may be difficult in bicuspid aortic valves (BAVs) when the commissure landmark is missing. There is also a potential risk of regurgitation over time due to presumed co-existent aortic disease and potentially progressive aortic dilatation in these patients. The use of FS should therefore be restrictive in patients with a BAV and an enlarged aorta. In consequence, the observation of root anatomy, correct sizing and symmetric implantation must be given particular attention. Another potential pitfall is associated with the implantation technique that uses three equidistant, intercommissural sutures at the nadir of each sinus that are placed at the corresponding part of the prosthetic cusps, using the pericardial strip available at the basis of the stentless valve. This technique firmly fixes the prosthesis to the aortic wall and deep bites into the aorta are necessary for permanent attachment. Particularly in the early phase of the learning curve, there might be reluctance to avoid too small suture bites and to judge the necessary aortic wall elasticity required for safe implantation. This could potentially explain the paravalvular leakage due to the dehiscent NCC in Case 4 or in the absence of any signs of prosthesis degeneration.

Four cases had presented with acute regurgitation due to vertical leaflet rupture. It is important to note that only the large size 25 and 27 prostheses were affected in our series, while it is strikingly that all tears were located in close proximity to the $\mathrm{NCC}$ / RCC or NCC/LCC commissure.

Due to their unrestricted design, stentless valves are fully exposed to the interaction between aortic root dynamics and valve mechanics. A flexible aortic root is thought to be essential for natural leaflet stress distribution. It was thus hypothesized that implantation of an unstented xenograft in a subcoronary, scalloped fashion that minimally disrupts aortic root dynamics would reduce dynamic stress on leaflets, translating into a lower probability of SVD [10]. In fact, however, the aortic root undergoes complex, asymmetric deformations during the various phases of the cardiac cycle, including aorto-ventricular and sinotubular strain and aortic root elongation, compression, shear and torsional deformation [10]. These deformations are not homogeneous for the three sinuses. The NCC sinus is usually larger with corresponding volume, height, width, leaflet size and thickness [11]. Consequently, the NC intercommissural length was found to undergo significantly more expansion (compared with the right and left intercommissural lengths) during the cardiac cycle [12], associated with peak stresses that are located at the free margin and belly near the coaptation surfaces [11]. In the sheep model, deformations at the STJ were symmetric and uniform, whereas there is heterogeneous shear and torsion deformation of the aortic root during the cardiac cycle, that is, one sinus twisting in the opposite direction than the other two [10]. Importantly, the LCC and NCC sinuses were found to undergo clockwise torsion, whereas the right sinus undergoes counterclockwise torsion during the ejection phase [10]. This puts stress on the NCC/RCC commissure and could explain why we only saw tears close to this particular location.

Caprili et al. reported a grossly calcified FS bioprosthesis that was replaced 18 months after the initial AVR. The authors suggested that, in this particular case, the positioning and symmetry in a dilated aorta $(37.5 \mathrm{~mm})$ could not be achieved perfectly. This could have led to increased mechanical stress on the cusps, accelerating mineralization [13]. In our series of 4 cases, gross calcification of the prostheses involved the whole aortic root including a shrunken and immobile annulus. Whereas a compliant aortic root contributes substantially to smooth and symmetrical leaflet opening with minimal gradients, this effect is strikingly absent with stiff roots and contributes to premature SVD [14]. Furthermore, the severe calcification and adhesions between the subcoronary stentless valve and the native aortic wall may require extensive dissection with the risk of damage to the coronary ostia, aortic wall and annulus. Unlike stented prostheses, the FS is attached directly to the aortic wall (with $\sim 5 \mathrm{~mm}$ of the pericardial sheet), potentially allowing chemical valve compounds to interact with aortic endothelial cells.

All biological tissue valves including the FS primarily undergo chemical fixation with GA to provide mechanical stability, at the 
expense of susceptibility to calcification [15]. In a unique treatment, Sorin uses HCA featuring strong electronegative sulphonic groups as post-fixation treatment bonding to neutralize free toxic aldehyde groups in the FS valve $[16,17]$. In a subcutaneous rat model, GA-HCA-treated bovine pericardium showed less calcification than GA alone after explantation (14-84 days) [16]. The effectiveness, however, has been questioned because this model ignores mechanical and dynamic stress or blood-surface contact [18]. In fact, results from the subcutaneous rat model were the exact opposite of those from the blood contact and the pulsatile models, emphasizing the necessity of blood contact in preclinical valve testing [18].

Prostheses with tears and cusp ruptures were relatively easy to replace. In contrast, cases with severe calcification turned out to require very difficult and demanding reoperations. FS valves were replaced with prostheses at least one size smaller than the FS, and it must be expected that root replacement will be necessary. Our experience is in agreement with a previous report that reoperations after stentless AVR are challenging, more complex procedures associated with increased operative risk compared with a redo AVR after implantation of other valve prostheses [4]. Alternatively, transcatheter heart valve aortic valve-in-valve implantation is likely to become increasingly important for the treatment of patients considered high risk or inoperable with degenerated and failing FS stentless bioprostheses. Despite the presumed hazards of ostial coronary obstruction, risk estimation and careful planning of the procedure are possible due to the known location and effective height of leaflets and following the determination of coronary ostia location [19].

The freedom from explantation for SVD in our cohort is 0.84 [0.70-0.92] and $0.76[0.50-0.89]$ after 8 and 9 years, respectively, comparable with similar data reported for the Toronto [20] and Biocor [21] stentless valves. However, after $\sim 10$ years, the freedom from SVD and reoperation dropped dramatically in earlier porcine models, such as the O'Brien (CryoLife, Atlanta, GA, USA) [22], Shelhigh (Shelhigh, Inc., Millburn, NJ, USA) [23], Biocor (St. Jude Medical, St. Paul, MN, USA) [21] and the Toronto SPV (St. Jude Medical, St. Paul, MN, USA) [20]. As a critical observation period now approaches, additional data from other centres will help to determine the FS long-term durability of the FS prosthesis and the concept of current third-generation stentless valves.

\section{Limitations}

This single-centre study shares the limitation of representing a selection of patients. Due to the advanced age in this typical cohort of patients undergoing AVR, a substantial number of patients did not reach the full observation time and died for reasons we are not always able to identify clearly. The true incidence of premature prosthesis failure may therefore be underestimated. Furthermore, some patients did develop relevant SVD, but declined surgical treatment. These valves were not available for analysis and thus cases that would have added to our understanding may have been missed. We introduced the FS particularly early after it had become available and our institution provided training and proctoring. Thus, information about design-related limitations was largely unavailable at the outset, and learning curves may have played a role. Because we report a case series from a single centre including valve-dependent and -independent failures, a final conclusion on the durability of the FS valve requires more data and reports on freedom from adverse events from other institutions.

\section{Conclusions}

In contrast to stented valves, stentless valve implantation is less reproducible and standardized, and requires more surgeondependent experience. The ideal patient has a symmetric aortic root and a trileaflet valve-sinus anatomy. The observation of root anatomy, correct sizing and symmetric implantation must be given particular attention, because any malpositioning can lead to tissue fatigue over time leading to SVD. The potential for better outcomes depends on optimal patient selection and observance of the limitations for the use of the FS. This case series of prosthesis explantation due to structural and non-structural valve dysfunction allows some recommendations for use. Both oversizing and undersizing have the potential to cause prosthesis failure. Furthermore, the use of FS should be restrictive in patients with BAV because of the missing commissure landmark and co-existing aortic wall pathology, as well as in enlarged aortas. Deep suture bites are necessary for safe attachment of the FS, depending, in part, on the aortic wall quality. A thinned and frail aorta and massive calcification of the aortic sinus wall and root are incompatible with FS.

\section{ACKNOWLEDGEMENTS}

We are grateful to Genie Lamont, Brigitta Gahl and Sara Baumberger for the excellent technical assistance in preparing and reviewing the manuscript, to Paul Libera for documentation and to Boris Leuenberger and his team for preparation of the histological pictures.

\section{Funding}

None declared.

Conflict of interest: none declared.

\section{REFERENCES}

[1] Lindman BR, Bonow RO, Otto CM. Current management of calcific aortic stenosis. Circ Res 2013;113:223-37.

[2] Kobayashi J. Stentless aortic valve replacement: an update. Vasc Health Risk Manag 2011;7:345-51.

[3] Schoen FJ, Levy RJ. Calcification of tissue heart valve substitutes: progress towards understanding and prevention. Ann Thorac Surg 2005;79:1072-80.

[4] Borger MA, Prasongsukarn K, Armstrong S, Feindel CM, David TE. Stentless aortic valve reoperations: a surgical challenge. Ann Thorac Surg 2007;84:737-44

[5] Aymard T, Eckstein F, Englberger L, Stalder M, Kadner A, Carrel T. The Sorin Freedom SOLO stentless aortic valve: technique of implantation and operative results in 109 patients. J Thorac Cardiovasc Surg 2010;139: 775-7.

[6] Repossini A, Rambaldini M, Lucchetti V, Da Col U, Cesari F, Mignosa C et al. Early clinical and haemodynamic results after aortic valve replacement with the Freedom SOLO bioprosthesis. Eur J Cardiothorac Surg 2012;41:1104-10.

[7] Edmunds LH, Clark RE, Cohn LH, Miller DC, Weisel RD. Guidelines for reporting morbidity and mortality after cardiac valvular operations. Ann Thorac Surg 1988;46:257-9.

[8] Scharfschwerdt M, Sievers $H J$, Hussein A, Kraatz EG, Misfeld M. Impact of progressive sinotubular junction dilatation on valve competence of the $3 \mathrm{~F}$ aortic and Sorin Solo stentless bioprosthetic heart valves. Eur J Cardiothorac Surg 2010;37:631-34. 
[9] David TE, Feindel CM, Bos J, Ivanov J, Armstrong S. Aortic valve replacement with Toronto SPV bioprosthesis: optimal patient survival but suboptimal valve durability. J Thorac Cardiovasc Surg 2008;135: 19-24.

[10] Dagum P, Green GR, Nistal FJ, Daughters GT, Timek TA, Foppiano LE et al. Deformational dynamics of the aortic root: modes and physiologic determinants. Circulation 1999;100:II54-62.

[11] Grande KJ, Cochran RP, Reinhall PG, Kunzelman KS. Mechanisms of aortic valve incompetence: finite element modeling of aortic root dilatation. Ann Thorac Surg 2000;69:1851-7.

[12] Lansac E, Lim HS, Shomura Y, Lim KH, Rice NT, Goetz WA et al. Aortic root dynamics are asymmetric. J Heart Valve Dis 2005;14:400-7.

[13] Caprili L, Fahim AN, Zussa C, Cristell DM. Very early malfunction of a large stentless aortic valve. Eur J Cardiothorac Surg 2009;36:417-8.

[14] Sripathi VC, Kumar RK, Balakrishnan KR. Further insights into normal aortic valve function: role of a compliant aortic root on leaflet opening and valve orifice area. Ann Thorac Surg 2004;77:844-51.

[15] Sinha P, Zurakowski D, Kumar TK, He D, Rossi C, Jonas RA. Effects of glutaraldehyde concentration, pretreatment time, and type of tissue (porcine versus bovine) on postimplantation calcification. J Thorac Cardiovasc Surg 2012;143:224-7.

[16] Valente M, Pettenazzo E, Thiene G, Molin GM, Martignago F, De Giorgi G et al. Detoxified glutaraldehyde cross-linked pericardium: tissue preservation and mineralization mitigation in a subcutaneous rat model. J Heart Valve Dis 1998;7:283-91.
[17] Stacchino C, Bona G, Bonetti F, Rinaldi S, Della Ciana L, Grignani A. Detoxification process for glutaraldehyde-treated bovine pericardium: biological, chemical and mechanical characterization. J Herat Valve Dis 1998;7:190-4

[18] Ozaki S, Herijgers P, Flameng W. Influence of blood contact on the calcification of glutaraldehyde-pretreated porcine aortic valves. Ann Thorac Cardiovasc Surg 2003;9:245-52.

[19] Stanger O, Gisler F, Correa Londono M. Valve-in-valve (ViV) procedures in patients with failed SOLO stentless valve prostheses. J Thorac Cardiovasc Surg 2014; in press.

[20] David TE, Ivanov J, Eriksson MJ, Bos J, Feindel CM, Rakowski H. Dilation of the sinotubular junction causes aortic insufficiency after aortic valve replacement with the Toronto SPV bioprosthesis. J Thorac Cardiovasc Surg 2001;122:929-34.

[21] Dellgren G, Eriksson MJ, Brodin LA, Rådegran K. Eleven years' experience with the Biocor stentless aortic bioprosthesis: clinical and hemodynamic follow-up with long-term relative survival rate. Eur J Cardiothorac Surg 2002;22:912-21.

[22] Pavoni D, Badano LP, lus F, Mazzaro E, Frassani R, Gelsomino $S$ et al Limited long-term durability of the Cryolife O'Brien stentless porcine xenograft valve. Circulation 2007;116:1307-13.

[23] Carrel TP, Schoenhoff FS, Schmidli J, Stalder M, Eckstein FS, Englberger L. Deleterious outcome of no-react-treated stentless valved conduits after aortic root replacement: why were warnings ignored? J Thorac Cardiovasc Surg 2008;136:52-7. 